\title{
Improving foot-and-mouth disease control using livestock movement patterns within the FMD protection zone of South Africa
}

\author{
David Lazarus ${ }^{1}$, Pamela Opperman ${ }^{2}$, Mohamed Sirdar ${ }^{2}$, Tanja Wolf ${ }^{3}$, Ilana van $\mathrm{Wyk}^{1}$, and \\ Oupa Rikhotso ${ }^{4}$
}

${ }^{1}$ University of Pretoria Faculty of Veterinary Science

${ }^{2}$ Agriculture Research Council, Onderstepoort Veterinary Research

${ }^{3}$ University of Pretoria Faculty of Natural and Agricultural Sciences

${ }^{4}$ Mpumalanga Provincial Government

August 17, 2020

\begin{abstract}
Foot-and-mouth disease (FMD) is a transboundary animal disease that has a major impact on livestock production, regional and international trade and livelihoods of smallholder farmers in endemic settings. Livestock movement is one of the most important ways of spreading infectious diseases including FMD. Many livestock diseases are transmitted through direct contact between animals, and thus between herds and flocks through animal movements. In this study, we described the pattern of livestock movements among smallholder farmers within a communal farming area in South Africa. A cross-sectional survey using a semi-structured questionnaire was administered to 116 respondents, and 13 focus group discussions employing participatory mapping and semi-structured interviews were conducted among smallholder goat farmers. Data from the study reported 37 nodes and 78 ties with an overall network density of 0.059 (SD 0.235) for goats, and 42 nodes and 90 ties with an overall network density of 0.052 (SD 0.223) for cattle across the study area. The study identified several FMD high-risk locations to prioritise vaccination programmes and targeted disease surveillance. Four locations within the (former) FMD-free zone of the country were identified to have connections with movement of goats from the study area. Findings from this study further demonstrated that goats are moved without official movement permits to the FMD free zone of the country, with most farmers being ignorant of the need to obtain official veterinary movement permits. These animal movements put the country at risk of future FMD outbreaks within the free zone. We recommend that the relevant authorities implement risk-based control measures to prevent the spread of infectious diseases.
\end{abstract}

\begin{abstract}
Foot-and-mouth disease (FMD) is a transboundary animal disease that has a major impact on livestock production, regional and international trade and livelihoods of smallholder farmers in endemic settings. Livestock movement is one of the most important ways of spreading infectious diseases including FMD. Many livestock diseases are transmitted through direct contact between animals, and thus between herds and flocks through animal movements. In this study, we described the pattern of livestock movements among smallholder farmers within a communal farming area in South Africa. A cross-sectional survey using a semi-structured questionnaire was administered to 116 respondents, and 13 focus group discussions employing participatory mapping and semi-structured interviews were conducted among smallholder goat farmers. Data from the study reported 37 nodes and 78 ties with an overall network density of 0.059 (SD 0.235 ) for goats, and 42 nodes and 90 ties with an overall network density of 0.052 (SD 0.223) for cattle across the study area. The study identified several FMD high-risk locations to prioritise vaccination programmes and targeted disease surveillance. Four locations within the (former) FMD-free zone of the country were identified to have connections with movement of goats from the study area. Findings from this study further
\end{abstract}


demonstrated that goats are moved without official movement permits to the FMD free zone of the country, with most farmers being ignorant of the need to obtain official veterinary movement permits. These animal movements put the country at risk of future FMD outbreaks within the free zone. We recommend that the relevant authorities implement risk-based control measures to prevent the spread of infectious diseases.

\section{Introduction}

Foot-and-mouth disease (FMD) is a highly infectious transboundary animal disease that affects clovenhoofed livestock and wildlife including cattle, buffalo, pigs, sheep, goats, impala, deer and antelope (OIE, 2018; Poolkhet et al., 2019). The disease is caused by infection with foot-and-mouth disease virus (FMDV), a single-stranded RNA virus in the genus Aphthovirus, family Picornaviridae (Han et al., 2018). Goats are the most common livestock species kept by smallholder communal farmers in South Africa. However, the clinical signs of FMD in goats have been described to be inapparent or mild with nasal discharge, ulcerative lesions of the oral mucosa and fever occurring in a proportion of animals (Lazarus et al., 2019). Goats affected by FMD also do not show obvious sickness behaviours (Wolf et al., 2020). Goats can be considered "silent shedders" of disease because of the lack of obvious clinical signs of FMD compared to some other cloven-hoofed animals.

FMDV is primarily transmitted through direct contact via inhalation (OIE, 2018; Poolkhet et al., 2019) and can be further spread through the movement of infected and susceptible hosts (Brito et al., 2017; Tekleghiorghis et al., 2016). Effective movement controls, such as those implemented during the 2001 FMD epidemic in the United Kingdom, can slow down the spread of disease (Ferguson et al., 2001; Haydon et al., 2004).

Risk factors for the occurrence and spread of FMD include poor farm biosecurity practices (Ellis-Iversen et al., 2011; Megersa et al., 2009), presence of infected animals (Gibbens et al., 2001), presence of wildlife reservoirs (Molla et al., 2010; Vosloo et al., 1996), exposure to secretions or products derived from infected animals (Elnekave et al., 2016), exposure to contaminated fomites (Alexandersen et al., 2003), poor vaccination coverage (Jori et al., 2009; Nyaguthii et al., 2019), longer vaccination intervals (Lazarus et al., 2017), poor livestock inspection (Jori et al., 2009) and unvaccinated animal populations (Bravo de Rueda et al., 2014).

Livestock movement is one of the most important ways of spreading infectious diseases between holdings (Nremark et al., 2011). Many livestock diseases are transmitted through direct contact between animals, and thus between herds and flocks through animal movements. This has caused many countries of the developed world to register livestock movements using national databases (Anonymous, 2014). Information generated from such databases could be used for surveillance and planning disease control programmes. The rapid analysis of livestock movements could also be used to implement effective movement restrictions.

The application of social network analysis within the livestock industry has improved our knowledge of livestock movement patterns and has informed risk-based surveillance systems (Dubé et al., 2008; Poolkhet et al., 2019). Social network analysis has been used extensively to analyse livestock movements (Aznar et al., 2011; Green et al., 2008; Kao et al., 2006; Kiss et al., 2008; Mweu et al., 2013; Nremark et al., 2011; Robinson et al., 2007; Webb, 2006), and can help identify targets for surveillance, intervention and control (Bajardi et al., 2012; Christley et al., 2005; Kiss et al., 2006; Natale et al., 2009). A network analysis study of the 2001 UK FMD outbreak (Shirley \& Rushton, 2005), identified livestock markets and dealers as the hubs for disease spread. Certain nodes (units of interests) like some farms, animal markets and dealers were key players in the early spread of FMD during the outbreak (Ortiz-Pelaez et al., 2006). All nodes had a high between-ness centrality, a measure of how frequent a node is located between each pair of node connections. Auction markets were key players for the spread of disease during this outbreak (Robinson \& Christley, 2007). A similar study in Denmark also reported that cattle markets influenced other nodes within the Danish cattle movement network (Mweu et al., 2013). The transportation of infected cattle is known to be responsible for disease transmission (Dubé et al., 2008) and the out-degree centrality, a quantification of the number of outgoing ties (links between nodes) from the node, is useful for estimating the resulting size of the outbreak. The control of infectious livestock diseases such as FMD should focus on livestock movements 
within the cattle trade network (Natale et al., 2009).

The aim of this study was to investigate the importance of livestock movements within the FMD protection zone of South Africa to identify high-risk locations for implementation of improved surveillance and strategic vaccination programmes.

\section{Materials and methods}

\subsection{Study area}

This study was conducted in the Mnisi Tribal Authority (MTA), a communal farming area within the FMD protection zone with vaccination in Bushbuckridge Local Municipality, Mpumalanga Province, South Africa (Figure 1). The MTA is divided into three animal health wards (Bushbuckridge East, Animal Health Wards I-III) and totals 16 communal dip tanks (livestock inspection points). Communal farmers within this area are involved mostly in livestock rearing. The proximity to the Kruger National Park (KNP) poses a threat to livestock production due to infectious diseases and the surrounding areas have poor market access as they are located within the FMD protection zone with vaccination (Lazarus et al., 2018).

FMD control measures in South Africa include the separation of wildlife and livestock using fences, clinical surveillance, routine vaccination of cattle and movement control of susceptible livestock, wildlife and their products (DAFF 2014). According to the South African veterinary legislation, three zones exist for the control of FMD (DAFF 2014). The three zones classify the country into: a) FMD infected zone b) FMD protection zone (with or without vaccination and c) formerly FMD free zone (majority of the country). The FMD protection zone protects the status of animals in the FMD free zone and movement of livestock into the free zone is restricted using a permit system after the animal has been examined and certified to be free from FMD.

Farmers within the protection zones are mostly engaged in communal farming activities, which are considered to be a cost-effective farming system (Dovie et al., 2006). However, it is a high-risk husbandry system due to poor biosecurity practices that might lead to the occurrence and spread of diseases including FMD. As a control measure for FMD and other infectious diseases, movement of cattle out of this zone of the country is only allowed if the animal originates from a herd that has evidence of previous FMD vaccination and has a movement permit issued by the official veterinary service. Thus, FMD vaccinated animals can only move to other vaccination areas or a designated abattoir for direct slaughter.

Between January and November 2019, two FMD serotype SAT2 outbreaks were reported in the formerly FMD free zone of Limpopo Province, (DAFF 2019a; DAFF 2019b). These outbreaks caused South Africa to lose the World Organisation for Animal Health (OIE) certified free zone status without vaccination.

\subsection{Target population and sample size calculations}

The target population was smallholder farmers who kept goats within the three animal health wards of the MTA. The required sample size was calculated based on the desire to estimate the proportion of respondents that reported small ruminant movement (in and out) of their flock at least once during a one-year period (July 2017 -June 2018). Given the lack of knowledge of small ruminant movements in the area, the proportion was assumed to be $50 \%$ and calculations were based on a desired confidence level of $95 \%$ and absolute error of $\pm 10 \%$. The sample size was estimated to be 97 respondents (Thrusfied, 2005) but increased by $5 \%$ to account for non-response and the possibility of data exclusions. Participants were selected proportional to the total number of registered livestock owners (stratified by small stock) per communal dip tank (Supplemental Table 1).

\subsection{Ethical considerations}

The study was approved by the University of Pretoria, Faculty of Veterinary Science, Animal Ethics Committee (Project Number V022-17) and the Faculty of Humanities, Ethics Committee (Project Number GW20170623HS). Participants were presented with a consent form before the commencement of interviews 
or focus group discussions and their identity was coded to ensure confidentiality. Verbal consent was obtained from illiterate respondents.

\subsection{Data collection}

\subsubsection{Questionnaire development and administration}

The questionnaire was pilot tested among 12 smallholder farmers from a community in Northwest Province, South Africa prior to finalization and administration in this study. The final questionnaire comprised a total of 21 questions divided into the following four sections: owner demographics, herd demographics, animal management and animal movement and losses. A combination of open and closed questions was used. For some questions, respondents were asked to choose only the most applicable answer, while for others they could select all appropriate options.

A semi-structured interview was administered in Xitsonga language using a trained interviewer. Smallholder goat farmers were individually recruited on a voluntary basis as they appeared for the weekly livestock inspection at the dip tanks. Respondents were enrolled after being informed of the study purpose. The interview session lasted approximately 30 minutes with each respondent. Interviews were conducted at the communal dip tanks, which is the usual meeting point for all farmers during the weekly livestock inspections. Global positioning system (GPS) coordinates for all study locations were captured using a handheld device (Garmin eTrex $\left.{ }^{\circledR} 10, \mathrm{USA}\right)$ at the time of the interview.

\subsubsection{Focus group discussions and participatory mapping}

For the focus group discussion and the participatory mapping, a semi-structured interview was conducted with separate groups at the communal dip tanks. Participants were recruited on a voluntary basis after being informed of the study purpose. Sessions were split into multiple groups with a maximum of 11 participants when group sizes were large. Respondents were requested to identify origins and destinations of livestock movement on a sketch map display of the MTA using laminated pictures of goats and cattle. Participants were further asked to list the origin and destinations of animal movements outside the three animal health wards. Questions were also asked concerning reasons for buying and selling animals and challenges faced in goat production. The local animal health technicians also participated in a group session to validate collected data and remove uncertain ties (origin and destination pairs) from the network.

\subsubsection{Additional animal health information}

Additional information concerning livestock distributions, inspection data and cattle vaccination coverage for the period preceding the study $(2017 / 2018)$ was reviewed from the local animal health technician's records.

\subsubsection{Network properties}

The network of goat and cattle movements in the three animal health wards of the MTA were analysed using directed and symmetrized methods (Borgatti et al., 2013). Nodes were the communities within the wards and the ties were live goat and cattle movements between communities. A descriptive statistical analysis was performed and network analysis was calculated on a directed binary network using UCINet6.66.4 (Analytical Technologies, USA) (Borgatti et al., 2013). The following indices were used for the calculation of the network centrality measures:

The degree centrality is the normalized value accounted for by analyzing the number of ties in each node. The node with a high value reflects a high number of ties or the channel of node connection. Directed networks are best described as either out-degree or in-degree centrality, based on whether the ties are directed away from a node or directed toward a recipient node.

The between-ness centrality is the Freeman normalized value, which is considered the shortest path between two nodes. The node with a high value indicated a high frequency of animal movements through the node.

The closeness centrality is a normalized value that is considered the geodesic distance from one node to all remaining nodes. A node with a high value indicated that it is easy to move animals to the linking node. 
The clustering coefficient is calculated from three connected nodes forming a triangular shape (transitivity) in the network. A network with a high clustering coefficient means that many node triangles are present.

The network density is the proportion of actual ties that are present in the network out of all possible ties.

\subsection{Data analysis}

Descriptive statistics were presented as frequencies and percentages. Continuous data were described either using mean \pm standard deviation or medians and interquartile ranges (IQR). The normality assumption for quantitative variables was assessed by calculating descriptive statistics, plotting histograms and performing the Anderson-Darling test for normality within MINITAB Statistical Software, Release 16 (Minitab Inc., USA). Normally distributed variables were presented as means \pm SD and comparisons performed using one-way ANOVA. Kruskal-Wallis tests were used to compare centrality measures across the three animal health wards of the study area. The Wilcoxon signed-rank test was used to compare centrality measures between goat and cattle movement networks. Statistical analyses were performed in commercially available software (IBM SPSS Statistics Version 24, International Business Machines Corp., Armonk, New York, USA) and significance was set at $\mathrm{P}<0.05$. Mapping of the study area displaying the distribution of dip tanks was performed using ArcGIS 10.2.3 (ESRI, USA), and the sociogram of network of goats and cattle movements network were performed using the UCINet6.66.4 programme (Analytical Technologies, USA) (Borgatti et al., 2013). Nodes were projected using their GPS coordinates estimated using Google Earth (https://www.google.com/earth/) when outside the study area.

\section{Results}

\subsection{Demographic and husbandry findings}

A total of 116 smallholder goat farmers were interviewed during June-July 2018, with 36 respondents from Ward I, 35 respondents from Ward II, and 45 respondents from Ward III. The median (IQR) age of respondents for the three wards was $62(53-75), 65(52-79)$ and $66(55-74)$ years for Wards I-III, respectively. The major occupation of respondents was livestock farming with some also involved in private or government employment (Table 1). In addition to rearing goats, some respondents also reared cattle, pigs and chickens. The median (IQR) experience in farming was $27(14-38), 28(11-28)$ and $19(10-27)$ years for Wards I-III, respectively. Eighty-three percent (30/36), $86 \%(30 / 35)$ and $80 \%(36 / 45)$ of respondents kept cattle in addition to goats in Wards I-III, respectively. Respondents from Ward I indicated that their motivation for farming included love for animals (31\%), subsistence (22\%), business (19\%), draught power (6\%), ceremonial and cultural purpose $(31 \%)$ and long-term savings and investment $(3 \%)$. For the respondents in Ward II, these included subsistence (51\%), love for animals (20\%), draught power (11\%), business (9\%) and long-term savings and investment (6\%). Motivating factors for respondents in Ward III included subsistence (42\%), business (22\%), love for animals (13\%), long terms savings and investment (11\%), ceremonial and cultural purposes $(7 \%)$ and draught power $(2 \%)$.

Age of respondents, level of education, farming experience and number of goats owned were not different among the three animal health wards (Table 2). A total of 134 participants attended the focus group discussions from across the three animal health wards, with $68 \%$ (91/134) males and $32 \%(43 / 134)$ females.

\subsection{Animal movements}

There were less reported movements into holdings based on questionnaire responses relative to movement out of the holdings during the previous 12 months (Table 3). Reported movement into holdings were 5 goats in Ward I, 17 goats in Ward II and 11 goats in Ward III. The corresponding number of movements for cattle was 12 heads of cattle in Ward 1, 6 heads of cattle in Ward II, and 5 heads of cattle in Ward III. Respondents from Ward I indicated the most recent time of animal movement into the holdings to be median $6(1-30)$ months for goats and median $2(1-7)$ months for cattle. The most recent time for animal movement into the holdings for respondents in Ward II were median $6(4-12)$ months for goats and median $8(3-12)$ months for cattle. Respondents in Ward III indicated a median time of $5(3-12)$ months for goats and only 2 months for cattle. Livestock movement out of the flock for the previous 12 months preceding the study 
was 45 goats and 30 heads of cattle in Ward I, 38 goats and 25 heads of cattle in Ward II and 36 goats and 35 heads of cattle in Ward III. The most recent reported time of animal movement out of the holdings were median $6(2-11)$ months for goats and median $2(1-7)$ months for cattle in Ward I, median $2(1-8)$ months for goats and median $3(2-9)$ months for cattle in Ward II, and median $4(1-6)$ months for goats and median $3(2-8)$ months for cattle in Ward III. Most of the respondents in all the study locations also indicated their ignorance on the need to obtain official veterinary movement permit to move goats and pigs from their holdings within this control zone (Table 3).

\subsection{Network analysis of goat movements}

Data from 116 questionnaires and 13 focused group discussions reported 37 nodes and 78 ties with an overall network density of $0.059(\mathrm{SD}=0.235)$ across the study area. Most of the nodes had connections with each other, with extension to nodes outside the study area (Figure 2). Village A in Ward I and Village F in Ward II had the largest in-degree centrality values of 9 and 7 respectively. Moreover, the first five nodes with the highest values for out-degree centrality were Village F (12), Village G (11), Village E (7), Village H (7), and Village I (7). Ten nodes had links with communities outside the study area and animals were routinely moved to these outside communities either for consumption or husbandry purposes. On average, the actors (respective nodes of the study network) had a degree of 2.11 for both in-degree and out-degree, which was quite low given that there were 37 actors in the network. Overall, the network had 16 nodes within the study area and 21 nodes outside the study area. Four locations within the FMD fee zone of the country (Nelspruit, Tzaneen, Barberton and Leboeng) had links with the movement of goats from the study area. The range of out-degree was slightly higher (minimum - maximum: $0-12$ ) than that of the in-degree $(0-9)$ with more variability across actors in the out-degree than the in-degree (standard deviation and variance). The network had an out-degree coefficient of variation of 154 and in-degree coefficient of variation of 89 . In this network, the out-degree graph centralization was $28 \%$ and the in-degree graph centralization was $20 \%$ of the theoretical maximums.

Closeness centrality measures indicated Villages F and G, both in Ward II to be the nodes with the highest out-degree closeness values followed by Village M in Ward III and Village E in Ward I. There was more variation in the out-closeness value relative to the in-closeness (minimum - maximum: $0-20.33$ ).

Villages F and H both in Ward II, Village E (Ward I) and Village O (Ward III) had the largest between-ness measures. There was a lot of variation in actor between-ness (range $0-175$; standard deviation $=37.34$ relative to a mean between-ness value of 17.18). Despite this, the overall network centralization was relatively low $(12.91 \%)$ with an overall graph clustering coefficient of 0.248 .

\subsection{Network analysis of cattle movements}

Overall, data from 116 questionnaires and 13 focused group discussions represented 42 nodes and 90 ties with an overall network density of $0.052(\mathrm{SD}=0.223)$. Most of the nodes had connections with each other, with extension to nodes outside the study area (Figure 3). Villages J and M both in Ward III, had the highest outdegree centrality values of 10 and 9, respectively. Giyani, a node in Limpopo Province and Thulamahashe, a node in Mpumalanga Province both had higher in-degree centrality measures of 12 and 8 respectively. Thirteen of the nodes $(87 \%)$ had links with communities outside of the study area. On average, the actors had a degree of 2.14 for both in-degree and out-degree, which was quite low given that there were 42 actors in the network. Overall, the network had 16 nodes within the study area and 26 nodes outside the study area. The range of in-degree was slightly higher (minimum - maximum: $0-12)$ than that of the out-degree $(0-$ 10 ) and there was little variability across actors in-degree and out-degree (in-degree mean $=2.14$, out-degree mean $=2.14$, in-degree $\mathrm{SD}=2.69$, out-degree $\mathrm{SD}=2.72$, and in-degree variance $=7.26$, out-degree variance $=7.41$ ). The network had an out-degree coefficient of variation of 127 and an in-degree coefficient of variation of 125 . The out-degree graph centralization was $20 \%$ and the in-degree graph centralization was $25 \%$ of the theoretical maximums.

Villages J and M (both in Ward III), and Villages E and A (both in Ward I) were the nodes with the highest out-degree closeness values. There was little difference between the in-closeness and out-closeness values for 
the network.

Village A (Ward I), and Villages I and F (both in Ward II) had larger between-ness measures compared to other nodes in the network. However, there was a large variation in actor between-ness (from $0-217$ ) relative to a mean between-ness value of 31.12. Despite this, the overall network centralization index was relatively low (12\%) and the network had an overall graph clustering coefficient of 0.129.

\subsection{Comparison of movement network centrality measures}

There were no significant differences of movement centrality measures among areas (Table 4). However, median out closeness and between-ness centrality measures for the network were different by species, with goat network having more out-closeness centrality $(\mathrm{P}=0.021)$ and cattle network having more between-ness centrality $(\mathrm{P}=0.008$; Table 5$)$.

\subsection{Additional animal health information and FMD history}

The number of goats and the inspection efficiency descriptively varied by dip tank. However, there was no significant difference in goat numbers among wards $(\mathrm{P}=0.277)$. The number of pigs in the study area was small and there was $100 \%$ inspection efficacy. Animal health Wards I and III, had fewer pigs relative to Ward II $(\mathrm{P}<0.001)$. Cattle FMD vaccination coverage for the period preceding the study descriptively varied by node (dip tank; Table 6$)$. The number of cattle within the three wards was not significantly different $(\mathrm{P}=$ 0.306). Cattle from Wards I and II had a descriptively longer inter-vaccination interval ( $>220$ days) than the 120-day inter-vaccination interval prescribed by South African veterinary services. During 2017, a SAT2 FMD outbreak was reported at Village E, a community within the animal health Ward I (OIE-WAHID, 2017). However, the outbreak was contained within the community without spreading to other nodes within the study area.

\section{Discussion}

The primary aim of this study was to evaluate the role that movement of livestock might play in the spread of FMD within a disease control area and identify high-risk disease locations for improved surveillance and strategic vaccination programmes. In this paper, the livestock movement networks were investigated because of our desire to improve FMD control in the country. It is expected that the results of this study will be useful for disease control through the implementation of risk-based surveillance and strategic vaccination in disease endemic countries prioritizing FMD protection zones and high-risk production sectors within their regions.

The number of goats kept by respondents in this study were similar to a smallholder study conducted in another part of the country (Braker et al., 2002). In addition to keeping goats, communal farmers also kept cattle and pigs, which are also susceptible hosts for FMD. Most communal farmers within the study area reported that they do not require livestock movement permits to move goats to neighboring and distant locations. This suggests a need to educate farmers concerning the risk of livestock movement out of disease control areas. Most goats are bred and consumed locally within the communities with some reported movements outside the study area.

Livestock movement contributes to the spread of infectious diseases from endemic to free zones (Nremark et al., 2011). In South Africa, the majority of the country was previously classified as FMD free (DAFF, 2014). The KNP and adjoining nature reserves were classified as part of the FMD infected zone due to the existence of wildlife reservoirs including the African buffalo (Syncerus caffer ) (DAFF, 2014). Communal farming areas surrounding the KNP were classified as the FMD protection zone with vaccination, where cattle are routinely inspected and vaccinated against FMD (Lazarus et al., 2018). Movement of livestock from the FMD protection zone to any other part of the country requires inspection and a movement permit (DAFF, 2014). In this study, respondents reported more movement of animals out of their holdings relative to movement into their holdings during the previous 12 months. The most influential nodes for goat movements were communities closer to urban settlements with an accessible road network. Villages F and G both in Ward II, had the highest out-degree centrality measures for goat movements, and thus were the most influential 
communities for the possible spread of diseases. Goat movement out of the holdings was independent of each other to reach everyone in the network as demonstrated by high out-closeness centrality measures.

Villages J and M, both in Ward III, were the most influential in the cattle movement network as demonstrated by their high out-degree centrality measures. The spread of infection is reportedly associated with out-degree centrality measures (Dubé et al., 2008). Consequently, the nodes with high out-degree centrality are spreaders of disease and are likely to increase the size of an epidemic. However, to prevent these nodes from spreading FMD, the local veterinary authority could give high priority to FMD control and vaccination within these communities. The cattle vaccination coverage for Villages $\mathrm{F}$ and $\mathrm{G}$ for the period preceding the study was $72.3 \%$ and $74.6 \%$ respectively. However, the median (IQR) time since last vaccination for the first five nodes with the highest out-degree centrality was $232(220-233)$ days and this should be interpreted relative to the desired 120-day inter-vaccination interval. This prolonged interval has been previously reported from the study area (Lazarus et al., 2017). Cattle within these nodes have exceeded the expected vaccination interval and thus there might be a high proportion of susceptible cattle present. The cattle movement network had high likelihood of being an intermediary to reach everyone in the network as demonstrated by the high between-ness centrality measures.

Village A had the highest in-degree centrality measure for the goat movement network followed by Villages $\mathrm{F}$ and $\mathrm{O}$, which suggests high-risk nodes for disease outbreak occurrence. The cattle vaccination coverage for these nodes varied from $72.3-93 \%$, but Villages $\mathrm{F}$ and A had prolonged inter-vaccination intervals. Therefore, more FMD surveillance should be focused on these nodes as they tend to receive more inward animal movements relative to all other nodes. Village $\mathrm{F}$ had a relatively high centrality measure for goat movement, and this might be due to its location and accessible road network compared to the more remote settings. Farmers in Village F tended to source goats from nearby nodes and then export them to distant locations. A similar movement pattern was previously described in the study of traditional cattle trade network in Tak Province, Thailand (Khengwa et al., 2017). In the current network, the out-degree graph centralization of the goat movement network is much greater than the in-degree graph centralization, and this suggests that there is proportionally more out-degree movement in this network. These communities require additional education on disease prevention and control. In terms of the network analysis, such communities could be described as the disease spreaders. Therefore, in the event of an FMD outbreak within the country, the relevant authorities should focus their disease control measures on nodes with higher out-degree centrality measures and middlemen involved in livestock movements.

The two nodes with the highest in-degree centrality measures for the cattle movement network were nodes outside of the study area, Giyani in Limpopo Province and Thulamahashe in Mpumalanga Province. Both nodes are associated with urban development and organized abattoirs and butcheries. Middlemen might therefore be key players in the movement of animals within this network. This is similar to a social network analysis of cattle movements in Kampong Cham, Kampong Speu and Takeo, Cambodia (Poolkhet et al., 2016). Implementing restrictions on trade activities and livestock movements from the nodes with high outdegree measures and the middlemen might limit the magnitude of disease spread to other nodes. In this network, farmers themselves could be effective disseminators of information to improve communication for the greater benefit of the network.

The between-ness centrality for the goat movement network was high for two nodes in Ward II and one node each in Wards I and III, reflecting the many steps connecting nodes to one another. Villages $\mathrm{F}$ and $\mathrm{H}$ both in Ward II, Village E in Ward I and Village O in Ward III, appear to be more important than the other nodes by this measure. This suggests that more animals pass through these nodes relative to the other nodes of the network. Interestingly, in 2017, a SAT2 FMD outbreak was reported in Village E (Ward I), one of the communities with high between-ness centrality measure for the goat movement network (OIE-WAHID, 2017).

In 2019, two SAT2 FMD outbreaks (DAFF, 2019a; DAFF, 2019b) were reported in the FMD free zone of Limpopo Province, which were linked to animal movements but not associated with the study area. However, on the $3^{\text {rd }}$ of March 2020, a SAT2 FMD outbreak was reported at Villages J, M and K (Ward 
III) which subsequently spread to Villages E and A (Ward I) by the second week of April, 2020 (Mr Solly Mokone, Animal Health Technician, personal communication). From our study, Villages J and M are the most influential nodes in cattle movements as demonstrated by their out-degree centrality measures. The rapid spread from the three initial villages is therefore consistent with the expectations based on the current findings.

Goats have been described to be "silent shedders" of FMD without showing obvious clinical signs and sickness behaviours. These facts make it very difficult to identify infected goats that might pose a threat for the spread of disease through animal movements. The results of this study indicate that goats are moved by communal farmers out of the study area without official movement permits, although, the absolute number of movements appears to be low. The study also identified communities at high risk of disease occurrence and communities that might play important roles in subsequent disease spread. Four locations in the (former) FMD free zone of the country (Nelspruit, Tzaneen, Barberton and Leboeng) were identified as having connections with movement of goats from the study area and this calls for careful monitoring to mitigate the potential spread of FMD from the FMD protection zone.

The results of this study should be interpreted considering several limitations. A goat identification system and an organized database are not in use within the study area, even though each ward has a small stock register. Therefore, it was not possible to verify the movement of individual animals. Animal movement data derived in this study were solely based on interviews and subject to recall bias and purposeful misinformation. We were unable to follow up each origin and destination reported by the respondents outside of the study area due to limited budgets and resources. Other limitations to the study include the limited study area and the lack of production records for the verification of herd additions and subtractions.

The results of this study suggest the need to improve control measures within FMD protection zones and highrisk production sectors in disease endemic countries. We recommend the following: control goat movements via official movement permit systems, establish organized goat auction points or markets to control trader activities, initiate traceable livestock identification systems, develop databases for livestock movements and improve surveillance and inspection of FMD in goats within FMD protection zones and regions with high-risk production sectors such as dairy industries.

Cattle entering communities with high in-degree measures should be properly inspected and ensured that they have originated from herds that were vaccinated against FMD. Farmers moving cattle from the communities with high out-degree measures should ensure that their animals are vaccinated against FMD and that they are inspected and issued official movement permits in compliance with the local disease control policy. Presented information could be used to improve FMD control not only within the study area, adoption in other rural settings of southern Africa could improve the progressive control of FMD in general.

\section{Funding}

This research was funded by the National Research Foundation (NRF), South Africa (Grant Number 90578 and 76734) with additional funding from the Peace Parks Foundation, under contract grant agreement (Project \#A0U199).

\section{Declaration of competing interest}

None of the authors has financial or personal relationship that could influence or bias the content of the paper.

\section{Acknowledgements}

The authors would like to thank Dr. Louise Biggs of the Hluvukani Animal Health Centre for her logistical support and assistance with planning during the study. Ms. Jeanette Wentzel of the Hans Hoheisen Wildlife Station for her logistical support and planning. Ms. Addlove Sekgobela, Ms. Violet Mathebula and Ms. Dimakatso Julia Sithole of the Mnisi Community Programme for their assistance with the administration 
of the questionnaire and facilitation of the focus group discussions. Mr. Jerry Ndlozi, Mr. Thabo Lekhuleni and Mr. Solly Mokone of the Mpumalanga Veterinary Services for their logistical support during fieldwork.

\section{Data availability statement}

The authors confirm that the data supporting the findings of this study are available within the article and its supplementary material.

\section{References}

Alexandersen, S., Zhang, Z., Donaldson, A. I., \& Garland, A. J. M. (2003). The pathogenesis and diagnosis of foot-and-mouth disease. Journal of Comparative Pathology , 129 (1), 1-36. https://doi.org/10.1016/S00219975(03)00041-0

Anonymous. (2014). 27.6.2014. Official Journal of the European Union, 2014 (653), 33-49.

Aznar, M. N., Stevenson, M. A., Zarich, L., \& León, E. A. (2011). Analysis of cattle movements in Argentina, 2005. Preventive Veterinary Medicine, 98 (2-3), 119-127. https://doi.org/10.1016/j.prevetmed.2010.11.004

Bajardi, P., Barrat, A., Savini, L., \& Colizza, V. (2012). Optimizing surveillance for livestock disease spreading through animal movements. Journal of the Royal Society Interface , 9 (76), 2814-2825. https://doi.org/10.1098/rsif.2012.0289

Borgatti SP, Everett MG, J. J. (2013). Analyzing social networks . Thousand Oaks: Sage.

Braker, M. J. E., Udo, H. M. J., \& Webb, E. C. (2002). Impacts of intervention objectives in goat production within subsistence farming systems in South Africa. South African Journal of Animal Sciences , 32 (3), 185-191. https://doi.org/10.4314/sajas.v32i3.3745

Bravo de Rueda, C., Dekker, A., Eblé, P. L., \& de Jong, M. C. M. (2014). Identification of factors associated with increased excretion of foot-and-mouth disease virus. Preventive Veterinary Medicine ,113 (1), 23-33. https://doi.org/10.1016/j.prevetmed.2013.10.005

Brito, B. P., Rodriguez, L. L., Hammond, J. M., Pinto, J., \& Perez, A. M. (2017). Review of the Global Distribution of Foot-and-Mouth Disease Virus from 2007 to 2014. Transboundary and Emerging Diseases ,64 (2), 316-332. https://doi.org/10.1111/tbed.12373

Christley, R. M., Pinchbeck, G. L., Bowers, R. G., Clancy, D., French, N. P., Bennett, R., \& Turner, J. (2005). Infection in social networks: Using network analysis to identify high-risk individuals. American Journal of Epidemiology , 162 (10), 1024-1031.

DAFF 2014. (2014). Veterinary Procedural Notice for FMD Control in South Africa . Pretoria.

DAFF 2019a. (2019). Positive foot-and-mouth disease results in the Vhembe District of Limpopo . Pretoria.

DAFF 2019b. (2019). Press Release: Positive foot-and-mouth disease result in the Molemole District, Limpopo, South Africa . Pretoria.

Dovie, D. B. K., Shackleton, C. M., \& Witkowski, E. T. F. (2006). Valuation of communal area livestock benefits, rural livelihoods and related policy issues. Land Use Policy , 23 (3), 260-271. https://doi.org/10.1016/j.landusepol.2004.08.004

Dubé, C., Ribble, C., Kelton, D., \& McNab, B. (2008). Comparing network analysis measures to determine potential epidemic size of highly contagious exotic diseases in fragmented monthly networks of dairy cattle movements in Ontario, Canada. Transboundary and Emerging Diseases , 55 (9-10), 382-392.

Ellis-Iversen, J., Smith, R. P., Gibbens, J. C., Sharpe, C. E., Dominguez, M., \& Cook, A. J. C. (2011). Papers: Risk factors for transmission of foot-and-mouth disease during an outbreak in southern England in 2007. Veterinary Record , 168 (5), 128. https://doi.org/10.1136/vr.c6364 
Elnekave, E., Van Maanen, C., Shilo, H., Gelman, B., Storm, N., Berdenstain, S., .. Klement, E. (2016). Prevalence and risk factors for foot and mouth disease infection in small ruminants in Israel. Preventive Veterinary Medicine , 125 (2015), 82-88. https://doi.org/10.1016/j.prevetmed.2015.12.019

Ferguson, N. M., Donnelly, C. A., \& Anderson, R. M. (2001). Transmission intensity and impact of control policies on the foot and mouth epidemic in Great Britain. Nature , 413 (6855), 542-548. https://doi.org/10.1038/35097116

Gibbens, J. C., Sharpe, C. E., Wilesmith, J. W., Mansley, L. M., Michalopoulou, E., Ryan, J. B. M., \& Hudson, M. (2001). Descriptive epidemiology of the 2001 foot-and-mouth disease epidemic in Great Britain: The first five months. Veterinary Record ,149 (24), 729-743. https://doi.org/10.1136/vr.149.24.729

Green, D. M., Kiss, I. Z., Mitchell, A. P., \& Kao, R. R. (2008). Estimates for local and movement-based transmission of bovine tuberculosis in British cattle. Proceedings of the Royal Society B: Biological Sciences , 275 (1638), 1001-1005. https://doi.org/10.1098/rspb.2007.1601

Han, L., Xin, X., Wang, H., Li, J., Hao, Y., Wang, M., ... Shen, C. (2018). Cellular response to persistent foot-and-mouth disease virus infection is linked to specific types of alterations in the host cell transcriptome. Scientific Reports , 8 (1), 1-13. https://doi.org/10.1038/s41598-018-23478-0

Haydon, D. T., Kao, R. R., \& Kitching, R. P. (2004). The UK foot-and-mouth disease outbreak - The aftermath. Nature Reviews Microbiology , 2 (8), 675-681. https://doi.org/10.1038/nrmicro960

Jori, F., Vosloo, W., Du Plessis, B., Bengis, R., Brahmbhatt, D., Gummow, B., \& Thomson, G. R. (2009). A qualitative risk assessment of factors contributing to foot and mouth disease outbreaks in cattle along the western boundary of the Kruger National Park. OIE Revue Scientifique et Technique , 28 (3), 917-931. https://doi.org/10.20506/rst.28.3.1932

Kao, R. R., Danon, L., Green, D. M., \& Kiss, I. Z. (2006). Demographic structure and pathogen dynamics on the network of livestock movements in Great Britain. Proceedings of the Royal Society B: Biological Sciences , 273 (1597), 1999-2007. https://doi.org/10.1098/rspb.2006.3505

Khengwa, C., Jongchansittoe, P., Sedwisai, P., \& Wiratsudakul, A. (2017). A traditional cattle trade network in Tak province, Thailand and its potential in the spread of infectious diseases. Animal Production Science , 57 (1), 152-160. https://doi.org/10.1071/AN15043

Kiss, I. Z., Green, D. M., \& Kao, R. R. (2006). The network of sheep movements within Great Britain: Network properties and their implications for infectious disease spread. Journal of the Royal Society, Interface / the Royal Society , 3 (10), 669-677.

Kiss, I. Z., Green, D. M., \& Kao, R. R. (2008). The effect of network mixing patterns on epidemic dynamics and the efficacy of disease contact tracing. Journal of the Royal Society Interface , 5 (24), 791-799. https://doi.org/10.1098/rsif.2007.1272

Lazarus, D. D., Fosgate, G. T., van Schalkwyk, O. L., Burroughs, R. E. J., Heath, L., Maree, F. F., ... Thomson, G. R. (2017). Serological evidence of vaccination and perceptions concerning Foot-and-Mouth Disease control in cattle at the wildlife-livestock interface of the Kruger National Park, South Africa. Preventive Veterinary Medicine , 147 , 17-25. https://doi.org/10.1016/j.prevetmed.2017.08.016

Lazarus, D. D., Mutowembwa, P. B., Sirdar, M. M., Rametse, T. M., Heath, L., Opperman, P. A., ... Fosgate, G. T. (2019). Clinical presentation of FMD virus SAT1 infections in experimentally challenged indigenous South African goats. Small Ruminant Research ,180 , 15-20. https://doi.org/10.1016/J.SMALLRUMRES.2019.09.014

Lazarus, D. D., van Schalkwyk, O. L., Burroughs, R. E. J., Mpehle, A., Reininghaus, B., Rikhotso, O., ... Fosgate, G. T. (2018). Serological responses of cattle inoculated with inactivated trivalent foot-and-mouth disease vaccine at the wildlife-livestock interface of the Kruger National Park, South Africa. Preventive Veterinary Medicine , 158 , 89-96. https://doi.org/10.1016/j.prevetmed.2018.08.003 
Megersa, B., Beyene, B., Abunna, F., Regassa, A., Amenu, K., \& Rufael, T. (2009). Risk factors for foot and mouth disease seroprevalence in indigenous cattle in Southern Ethiopia: The effect of production system. Tropical Animal Health and Production , 41 (6), 891-898. https://doi.org/10.1007/s11250-008-9276-5

Molla, B., Ayelet, G., Asfaw, Y., Jibril, Y., Ganga, G., \& Gelaye, E. (2010). Epidemiological study on foot-and-mouth disease in cattle: Seroprevalence and risk factor assessment in south omo zone, southwestern Ethiopia. Transboundary and Emerging Diseases ,57 (5), 340-347. https://doi.org/10.1111/j.18651682.2010.01154.x

Mweu, M. M., Fournié, G., Halasa, T., Toft, N., \& Nielsen, S. S. (2013). Temporal characterisation of the network of Danish cattle movements and its implication for disease control: 2000-2009.Preventive Veterinary Medicine , 110 (3-4), 379-387. https://doi.org/10.1016/j.prevetmed.2013.02.015

Natale, F., Giovannini, A., Savini, L., Palma, D., Possenti, L., Fiore, G., \& Calistri, P. (2009). Network analysis of Italian cattle trade patterns and evaluation of risks for potential disease spread.Preventive Veterinary Medicine ,92 (4), 341-350. https://doi.org/10.1016/j.prevetmed.2009.08.026

Nremark, M., Hkansson, N., Lewerin, S. S., Lindberg, A., Jonsson, A., Nöremark, M., ... Jonsson, A. (2011). Network analysis of cattle and pig movements in Sweden: Measures relevant for disease control and risk based surveillance. Preventive Veterinary Medicine ,99 (2-4), 78-90. https://doi.org/10.1016/j.prevetmed.2010.12.009

Nyaguthii, D. M., Armson, B., Kitala, P. M., Sanz-Bernardo, B., Di Nardo, A., \& Lyons, N. A. (2019). Knowledge and risk factors for foot-and-mouth disease among small-scale dairy farmers in an endemic setting. Veterinary Research , 50 (1). https://doi.org/10.1186/s13567-019-0652-0

OIE-WAHID. (2017). World Animal Health Information Database Interface (WAHID). Retrieved April 29, 2019, from Bushbuckridge FMD Outbreak Report website: https://www.oie.int/wahis_2/public/wahid.php/Reviewreport/Review?page_refer=MapFullEventReport\&reportid=13947

OIE World Organisation for Animal Health. (2018). Foot and Mouth disease (FMD). Retrieved April 23, 2019, from Animal Health in the World website: http://www.oie.int/en/animal-health-in-the-world/animaldiseases/Foot-and-mouth-disease/

Ortiz-Pelaez, A., Pfeiffer, D. U., Soares-Magalhães, R. J., \& Guitian, F. J. (2006). Use of social network analysis to characterize the pattern of animal movements in the initial phases of the 2001 foot and mouth disease (FMD) epidemic in the UK. Preventive Veterinary Medicine ,76 (1-2), 40-55.

Poolkhet, C., Kasemsuwan, S., Seng, S., Keartha, C., Sokmao, C., Shin, M., ... Hinrichs, J. (2016). Social network analysis of cattle movement in Kampong Cham, Kampong Speu and Takeo, Cambodia. Acta Tropica , 159 , 44-49. https://doi.org/10.1016/j.actatropica.2016.03.027

Poolkhet, Chaithep, Kasemsuwan, S., Phiphakhavong, S., Phouangsouvanh, I., Vongxay, K., Shin, M. S., ... Hinrichs, J. (2019). Social network analysis for the assessment of pig, cattle and buffalo movement in Xayabouli, Lao PDR. PeerJ , 6 (1), e6177. https://doi.org/10.7717/peerj.6177

Robinson, S. E., \& Christley, R. M. (2007). Exploring the role of auction markets in cattle movements within Great Britain.Preventive Veterinary Medicine, 81 (1-3 SPEC. ISS.), 21-37.

Robinson, S. E., Everett, M. G., \& Christley, R. M. (2007). Recent network evolution increases the potential for large epidemics in the British cattle population. Journal of the Royal Society Interface , 4 (15), 669-674. https://doi.org/10.1098/rsif.2007.0214

Shirley, M. D. F., \& Rushton, S. P. (2005). Where diseases and networks collide: Lessons to be learnt from a study of the 2001 foot-and-mouth disease epidemic. Epidemiology and Infection , 133 (6), 1023-1032. https://doi.org/10.1017/S095026880500453X 
Tekleghiorghis, T., Moormann, R. J. M., Weerdmeester, K., \& Dekker, A. (2016). Foot-and-mouth Disease Transmission in Africa: Implications for Control, a Review. Transboundary and Emerging Diseases ,63 (2), 136-151. https://doi.org/10.1111/tbed.12248

Thrusfied M. (2005). Domestic testing. In Veterinary Epidemiology . Oxford, UK.

Vosloo, W., Bastos, A. D., Kirkbride, E., Esterhuysen, J. J., Van Rensburg, D. J., Bengis, R. G., .. Thomson, G. R. (1996). Persistent infection of African buffalo (Syncerus caffer) with SAT-type foot-and-mouth disease viruses: rate of fixation of mutations, antigenic change and interspecies transmission. The Journal of General Virology , 77 ( Pt 7) (7), 1457-1467. Retrieved from http://www.ncbi.nlm.nih.gov/pubmed/8757987

Webb, C. R. (2006). Investigating the potential spread of infectious diseases of sheep via agricultural shows in Great Britain.Epidemiology and Infection , 134 (1), 31-40. https://doi.org/10.1017/S095026880500467X

Wolf, T. E., Lazarus, D. D., Opperman, P., Heath, L., Ganswindt, A., \& Fosgate, G. T. (2020). Impact of foot-and-mouth-disease on goat behaviour after experimental infection with serotype SAT1 virus.Preventive Veterinary Medicine , 176 , 104912. https://doi.org/10.1016/j.prevetmed.2020.104912 


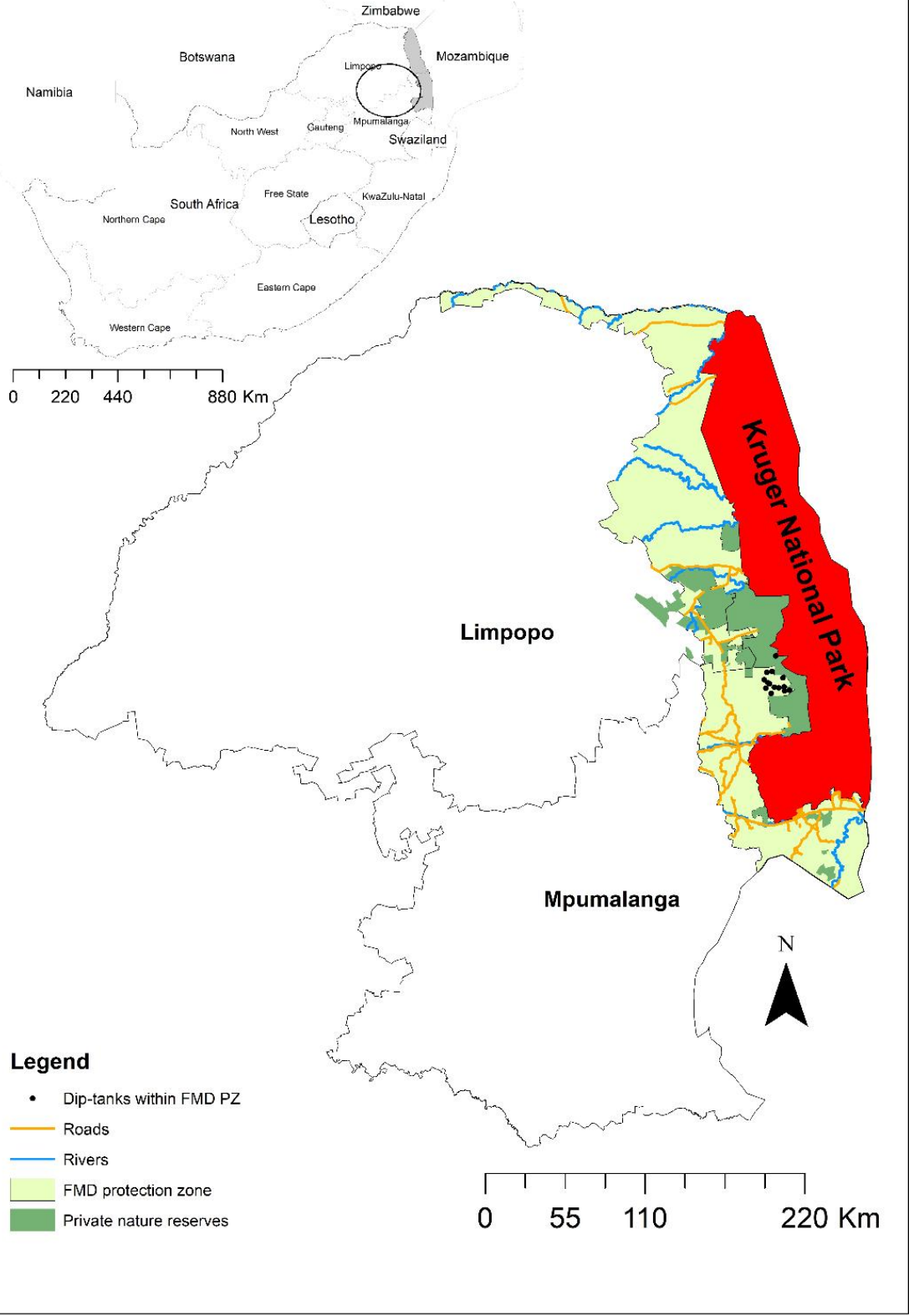



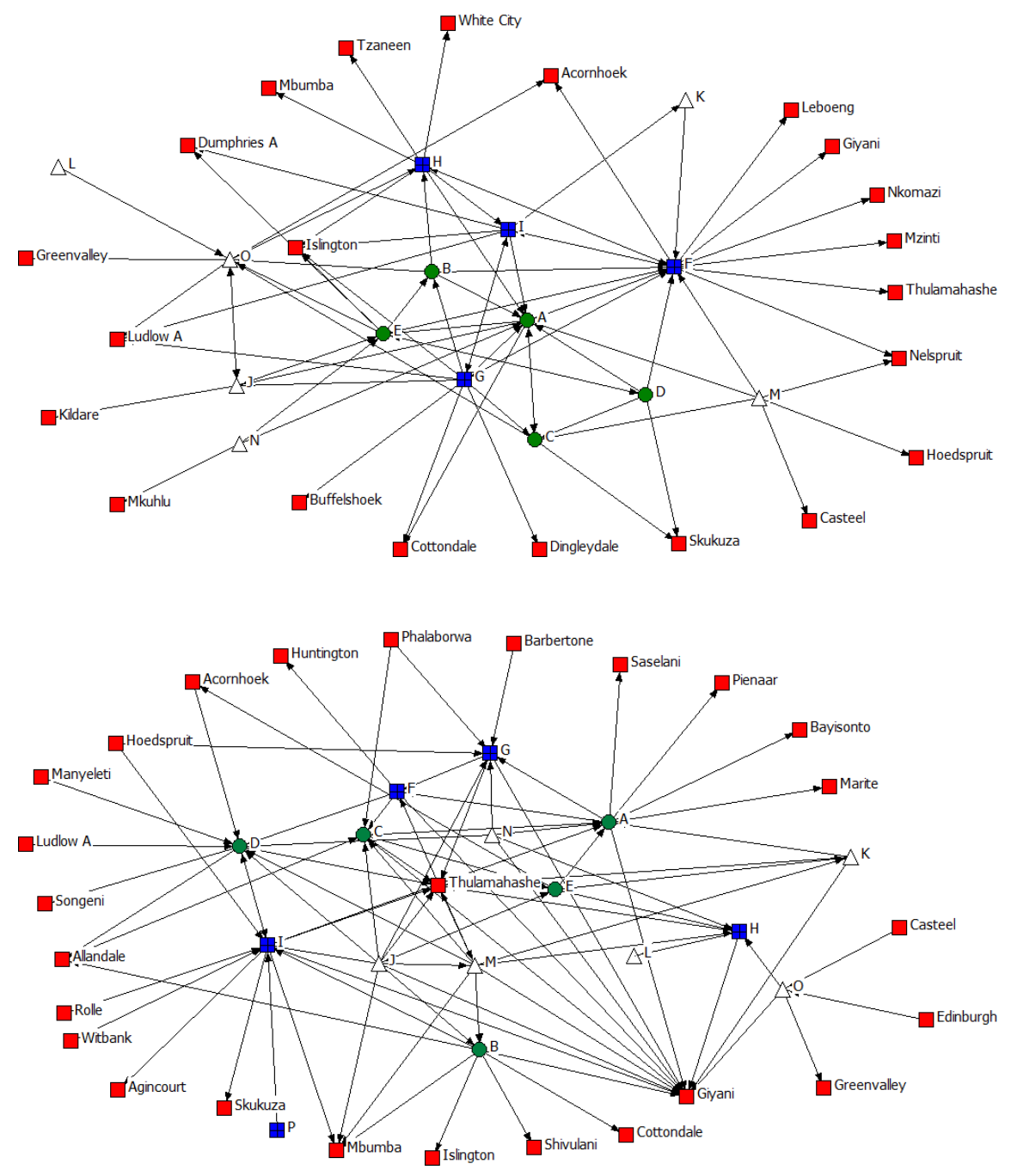

\section{Hosted file}

Lazarus et al. TBED_2020_Table 1-6.docx available at https://authorea.com/users/351393/ articles/476042-improving-foot-and-mouth-disease-control-using-livestock-movementpatterns-within-the-fmd-protection-zone-of-south-africa 